\title{
SURGICALLY CREATED DOUBLE-ORIFICE LEFT ATRIOVENTRICULAR VALVE: A VALVE-SPARING REPAIR IN SELECTED ATRIOVENTRICULAR SEPTAL DEFECTS
}

Loïc Macé, MD

Patrice Dervanian, $\mathrm{MD}^{\mathrm{a}}$

Lucile Houyel, $\mathrm{MD}^{\mathrm{b}}$

Evelyne Chaillon-Fracchia, $\mathrm{MD}^{\mathrm{b}}$

Dominique Piot, $\mathrm{MD}^{\mathrm{a}}$

Virginie Lambert, $\mathrm{MD}^{\mathrm{a}}$

Jean Losay, MD

Jean-Yves Neveux, MD
Objectives: Some features of the left atrioventricular valve (large mural leaflet, dystrophic tissue) represent a challenge for repair of atrioventricular septal defects without postoperative regurgitation. A retrospective study was conducted to evaluate the results of surgically creating a double-orifice left atrioventricular valve in such circumstances. Clinical results were analyzed according to valvular and subvalvular left atrioventricular valve measurements in pathologic specimens with atrioventricular septal defects.

Methods: Among 157 patients operated on for atrioventricular septal defect since October 1989, 10 patients underwent primary repair $(n=8)$ or reoperation $(n=2)$ by this procedure. Median age at repair was 3.3 years $(0.1-33$ years). Anatomic types were complete $(n=3)$, intermediate $(n=5)$, and partial $(n=2)$. Preoperative moderate to severe left atrioventricular valve regurgitation was present in 6 patients. After the repair (two-patch technique in complete atrioventricular septal defect, cleft closed in each case), these 10 patients were found to have moderate to severe residual regurgitation not amenable to repair by annuloplasty. The top edge of the mural leaflet was anchored to the facing free edge of the cleft.

Results: No hospital death or morbidity was observed. Left atrioventricular valve regurgitation was absent or trivial (8 patients) and mild (2 patients). Color-coded echocardiography did not show significant left atrioventricular valve stenosis. The mean diastolic pressure gradient across the left atrioventricular valve was $3.2 \pm 1.1 \mathrm{~mm} \mathrm{Hg}(1.4-4.5 \mathrm{~mm} \mathrm{Hg})$. At a median follow-up of 72 months (6-91 months), there was 1 late death, unrelated to left atrioventricular valve malfunction, due to pulmonary vascular obstructive disease. Left atrioventricular valve regurgitation did not increase over time, except in 1 patient in whom regurgitation recently progressed from mild to moderate. At rest, the mean diastolic pressure gradient across the left atrioventricular valve was $3.8 \pm 2.9 \mathrm{~mm} \mathrm{Hg}(1.5-11.2 \mathrm{~mm} \mathrm{Hg})$. One child had an early moderate stenosis without pulmonary hypertension. Studies on pathologic specimens $(n=34)$ indicated that long chordal lengths and large mural leaflet size are essential independent anatomic features to assess its feasibility.

Conclusions: Surgical creation of a double-orifice left atrioventricular valve is an effective additional procedure for repair of atypical cases of atrioventricular septal defect. The operation may decrease the need for reoperation or left atrioventricular valve replacement. (J Thorac Cardiovasc Surg $2001 ; 121: 352-65)$
From the Department of Cardiovascular and Pediatric Cardiac Surgery, ${ }^{\mathrm{a}}$ Cardiopathologic Laboratory, ${ }^{\mathrm{b}}$ Marie Lannelongue Hospital, Paris-Sud University, Paris, France.

Read at the Eightieth Annual Meeting of The American Association for Thoracic Surgery, Toronto, Ontario, Canada, April 30-May 3, 2000.

Received for publication May 4, 2000; revisions requested June 16, 2000; revisions received Aug 21, 2000; accepted for publication Sept 19, 2000.
Address for reprints: Loïc Macé, MD, Département de Chirurgie Cardiovasculaire et Cardiaque Pédiatrique, Hôpital Marie Lannelongue, 133, avenue de la Résistance, 92350 Le Plessis Robinson, France (E-mail: mace@ccml.com).

Copyright ( $\odot 2001$ by The American Association for Thoracic Surgery

$0022-5223 / 2001 \$ 35.00+0 \quad \mathbf{1 2 / 6 / 1 1 1 9 6 9}$

doi:10.1067/mtc.2001.111969 
$\mathrm{R}^{\mathrm{e}}$ econstruction of the left atrioventricular valve (LAVV) is the critical part of the repair of atrioventricular septal defects (AVSDs). Residual LAVV regurgitation is a risk factor for early and late morbidity and mortality. ${ }^{1,2}$ Regardless of the techniques used, some structural features of LAVV represent a challenge for repair without postoperative regurgitation: (1) a large mural leaflet, generally associated with a diminutive left inferior leaflet ${ }^{3,4}$; (2) forms with separate orifices $^{3,5-9}$; (3) presence of dystrophic valve tissue; and (4) anomalies of the subvalvular apparatus. ${ }^{5,10}$ Technical improvements were described to avoid the anticipated requirement for an LAVV replacement or tolerance for a significant residual regurgitation: (1) a two-patch repair without division of the bridging leaflets to avoid LAVV distortion and sandwiching the valves between patches to decrease the chances of dehiscence ${ }^{11-13}$; (2) the preference for a "cleft" or "septal commissure" closure when the application of the three-leaflet repair ${ }^{14}$ is not mandatory (ie, small mural leaflet, single papillary muscle); (3) realization of commissural, ${ }^{15}$ segmental, ${ }^{4}$ or circumferential ${ }^{16}$ annular annuloplasties; and (4) patch augmentation of the superior and inferior leaflets to improve the coaptation with the mural leaflet. ${ }^{17}$

The purpose of this retrospective study was to evaluate the suitability of a surgically created double-orifice LAVV, using the edge-to-edge technique, ${ }^{18-20}$ performed in cases of moderate to severe residual regurgitation associated with a large mural leaflet angular size, dystrophic tissue valve, and the presence of two wellformed papillary muscles. This technique was used only as a valve-sparing AVSD repair. In addition, clinical results were compared with an anatomic study on pathologic specimens to determine the potential feasibility of the procedure.

\section{Patients and methods}

Patients. From October 1989 to October 1999, of 157 consecutive patients (excluding patients with isolated mitral "cleft"), 10 patients (6.4\%) underwent AVSD repair with a surgically created double-orifice LAVV. Patients were selected on an intraoperative basis for this additional technique, when a residual moderate to severe LAVV regurgitation was present. The first procedure was performed in August 1992 (Table I). Anatomic types ${ }^{12,21,22}$ were partial $(n=2)$, intermediate $(\mathrm{n}=5)$, and complete $(\mathrm{n}=3)$, representing, respectively, $3.9 \%, 12.8 \%$, and $4.9 \%$ of the corresponding anatomic types of the entire series ( $\chi^{2}$ test, $P=.28$ ).

Patient profiles are described in Table I. Median age at repair was 3.3 years $(8.9 \pm 11.5$ years $)$. Median weight was $11.7 \mathrm{~kg}(19.5 \pm 18.2 \mathrm{~kg})$. There were 6 female patients and 4 male patients. Down syndrome was present in 4 patients. AVSD with separate orifices (ie, partial and intermediate
AVSD) had primary repairs. Conversely, in AVSD with a common orifice (ie, complete AVSD), this procedure was performed as a redo operation in 2 patients ( 1 early and 1 late failure) or after a previous pulmonary artery banding performed at 11 months of age. In this last patient, a lung biopsy showed grade II-III pulmonary arteriolar histologic changes according to the Heath-Edwards classification.

Preoperative diagnosis was made by means of echocardiography $(n=4)^{11}$ or both echocardiography and cardiac catheterization $(n=6)$. High pulmonary vascular resistances were present in 2 patients (patients 3 and 6). Preoperative LAVV regurgitation was severe $(n=4)$, moderate $(n=2)$, mild $(n=2)$, and trivial $(n=1)$. However, when this procedure was performed as an early reoperation, the grade of LAVV regurgitation progressed from mild (before the repair) to severe before the reoperation (Table II).

Operative technique. Cardiopulmonary bypass was established between the ascending aorta and both venae cavae. Myocardial protection was achieved by means of moderate systemic hypothermia, cold crystalloid antegrade cardioplegia, repeated every 20 minutes, and topical cooling. Mean extracorporeal time was $152 \pm 32$ minutes and mean aortic crossclamping time was $110 \pm 23$ minutes.

Complete AVSDs were operated on by means of a twopatch repair (polytetrafluorethylene patch/VSD; heterologous pericardial patch/ostium primum defect) without dividing the bridging leaflets. ${ }^{11-13}$ The VSD patch width was slightly smaller than the VSD itself to prevent annular dilatation. ${ }^{23}$ After the patch had been fixed onto the right aspect of the septal crest, its base was cut in a concave shape so as to fit exactly in depth with the LAVV tissue, which was simultaneously assessed with an injection of cold saline solution into the left ventricle (Fig 1). Then, the LAVV was sandwiched between the two patches by interrupted U-shaped sutures. Chordae tendineae were preserved except in a few cases at the level of the right inferior leaflet. For intermediate AVSDs, the VSD was closed directly $(n=4)$ or with a pericardial patch placed underneath the superior leaflet $(n=1)$. In patients with separate orifices, the suture line of the ostium primum patch was fixed onto the right components or on the right aspect of the septal crest in case of a diminutive right superior leaflet. The coronary sinus flow was always directed toward the left atrium. ${ }^{13}$

LAVV competence was tested by injection of cold saline solution under pressure into the left ventricle through a transvalvular catheter, after insertion of both patches. Additional procedures necessary to improve the competency of the LAVV included (1) "cleft" or "septal commissure" closure $(\mathrm{n}=10)$ and closure of an accessory cleft $(\mathrm{n}=3),{ }^{5}(2)$ unilateral $(n=1)$ or bilateral commissural annuloplasty $(n=2),{ }^{15}$ (3) additional annular annuloplasty facing the mural leaflet $(n=2),(4)$ resection of secondary chordae depending on the left inferior leaflet $(n=2),{ }^{14}(5)$ shortening of marginal chordae inserted at the top edge of the mural leaflet with implantation of artificial polytetrafluoroethylene chordae $(n=1)$, and (6) resection of accessory tissue valve with interchordal space fenestration $(n=1)$. 
Table I. Patient profiles

\begin{tabular}{lcccccc}
\hline Patient & Age $(y)$ & Body weight $(\mathrm{kg})$ & Down syndrome & Date of operation $($ moly) & AVSD type & Previous operation \\
\hline 1 & 0.1 & 3.9 & No & $8 / 92$ & Partial & - \\
2 & 26 & 54 & No & $10 / 92$ & Intermediate & - \\
3 & 9.5 & 19 & Yes & $11 / 92$ & Intermediate & - \\
4 & 4.6 & 14 & No & $2 / 93$ & Intermediate & Repair 04/93 \\
5 & 0.3 & 5.3 & No & $5 / 93$ & Rastelli type A & PA banding 04/93 \\
6 & 2 & 9.4 & Yes & $5 / 94$ & Rastelli type C & - \\
7 & 33 & 51 & No & $11 / 94$ & Partial & - \\
8 & 2 & 8.3 & Yes & $4 / 96$ & Intermediate & Repair 03/90 \\
9 & 9.9 & 21 & Yes & $6 / 99$ & Rastelli type A & - \\
10 & 1.2 & 9.2 & No & $8 / 99$ & Intermediate & - \\
\hline
\end{tabular}

$P A$, Pulmonary artery.

Table II. LAVV status

\begin{tabular}{|c|c|c|c|c|c|c|c|c|}
\hline \multirow[b]{2}{*}{ Patient } & \multirow{2}{*}{$\begin{array}{c}\text { Preop } \\
L A V V \\
\text { regurg. } \\
\text { (grade) }\end{array}$} & \multicolumn{2}{|c|}{ Postop } & \multicolumn{4}{|c|}{ Follow-up } & \multirow[b]{2}{*}{ Outcome } \\
\hline & & $\begin{array}{l}L A V V \\
\text { regurg. } \\
\text { (grade) }\end{array}$ & $\begin{array}{c}M D G \\
(m m \mathrm{Hg})\end{array}$ & $\begin{array}{l}L A V V \\
\text { regurg. } \\
\text { (grade) }\end{array}$ & $\begin{array}{c}M D G \\
(m m ~ H g)\end{array}$ & $\begin{array}{c}\text { Surface } \\
\left(\mathrm{cm}^{2}\right)\end{array}$ & $\begin{array}{l}\text { Follow-up } \\
\text { (то) }\end{array}$ & \\
\hline 1 & 4 & 1 & 2.5 & 1 & 1.5 & 2 & 91 & Asymptomatic-no Tt \\
\hline 2 & 2 & 1 & 3.6 & 1 & 2.5 & 2.8 & 89 & Asymptomatic-no Tt \\
\hline 3 & 3 & 1 & 4.2 & 1 & 4.5 & 1.75 & 87 & Asymptomatic-no Tt \\
\hline 4 & 3 & 1 & 2.7 & 1 & 4.9 & 1.5 & 84 & Asymptomatic $-\mathrm{no} \mathrm{Tt}$ \\
\hline 5 & $2(4 *)$ & 2 & 3.2 & 2 & 3 & NA & 81 & Asymptomatic-no Tt \\
\hline 6 & 1 & 0 & 4 & 0 & 2.1 & NA & 36 & Died/unrelated \\
\hline 7 & 4 & 2 & 4.2 & 3 & 5 & 2.1 & 63 & Reoperation LAVV regurg. \\
\hline 8 & 2 & 0 & 1.7 & 0 & 1.5 & 2.75 & 46 & Asymptomatic - no Tt \\
\hline 9 & 4 & 1 & 4.5 & 1 & 11.2 & 1.15 & 9 & Improved-no $\mathrm{Tt}$ \\
\hline 10 & 4 & 1 & 1.4 & 1 & 1.6 & 2.45 & 6 & Asymptomatic-no Tt \\
\hline
\end{tabular}

LAVV regurg., Left atrioventricular valve regurgitation; $N A$, not available; $M D G$, mean diastolic gradient; $T t$, medical treatment. Grade 1 (trivial), 2 (mild), 3 (moderate), and 4 (severe).

*Patient with a preoperative mild regurgitation, which became severe before the early reoperation in which a double-orifice repair was performed.

At that time, the LAVV, always associated with a large mural leaflet angular size (superior to $120^{\circ}$ in 6 patients), still had moderate to severe regurgitation. Two well-formed papillary muscles were always present and could be classified, according to Uemura and associates, ${ }^{24}$ as having a parallel arrangement $(n=6)$, an anterior displacement $(n=1$, patient $10)$, or a posterior displacement ( $\mathrm{n}=4$, patients $1,3,4$, and 6$)$ (Fig 2). The regurgitant jet was central. The mechanism was judged to be a lateral displacement $(n=2)$ (ie, a valve leaflet malalignment unrelated to the cleft closure), an anteroposterior defect in coaptation $(\mathrm{n}=1)$, or a combination of these two mechanisms $(n=7)$ at the level of the top edge of the mural leaflet (Fig 3, A). In the patient with a true prolapse of the mural leaflet, classic repair techniques (ie, chordal shortening and implantation of artificial chordae tendineae) did not decrease the degree of regurgitation. Etiology of this defect in coaptation was related to a dystrophic aspect of the valvular tissue, either native $(n=3)$, degenerative $(n=6)$, or iatrogenic $(\mathrm{n}=1)$, in the patient with an early reoperation for tissue disruption at the level of the superior component. The second repair was performed with pericardial patch augmentation of the left superior leaflet, leading to a distortion of the LAVV.

The double orifice was created by anchoring the free top edge of the mural leaflet to the facing free edge of the cleft with interrupted 6-0 to 4-0 polypropylene sutures $(n=8)$ or interrupted and mattress sutures reinforced with pledgets $(\mathrm{n}=2)$ (Fig 3, B). Hegar dilators were used for intraoperative sizing. The combined orifice area measured more than $70 \%$ to $80 \%$ of the expected mitral valve area for a patient of the same weight and age. However, these measurements must be taken with caution because of the slit-like appearance of the valvular orifices instead of a round aspect. The risk of LAVV stenosis was assessed by insertion of a left atrial catheter and transesophageal echocardiography in the last 3 patients. The remainder of the operation was conducted in the usual manner.

Follow-up. The follow-up study was performed over a 2month period (February-March 2000) by direct contact with the referring physician and patients or their parents. The last echocardiogram was done less than 6 months ago when the 
follow-up time was greater than 2 years and less than 2 months ago when the follow-up time was less than 2 years.

Echocardiographic assessment of LAVV regurgitation was based on a subjective scale depending on the retrograde extension of color flow toward the left atrium. Flow could be trivial (no extension), mild (no extension beyond the middle of the left atrium), moderate (extension toward the roof the left atrium), and severe (extension onto the roof of the left atrium with eventually a reverse flow in the pulmonary veins). Analysis of the grade of regurgitation also took into account the regurgitation jet characteristics (proximal jet size and surface of the color Doppler flow).

Mean diastolic LAVV gradient was assessed by Doppler ultrasonography, which is known to be reliable in the absence of a residual left-to-right shunt. LAVV area was measured by Doppler half-time pressure (results correlated with planimetry in the 3 adult patients). A moderate stenosis was defined as a mitral valve area between 1 and $1.4 \mathrm{~cm}^{2}$ and a severe stenosis as an area less than $1 \mathrm{~cm}^{2}$.

Pathologic specimens. From the 78 specimens with AVSD among the cardiopathologic collection at Marie Lannelongue Hospital, 34 hearts were analyzed for the purpose of this study. Hearts with single papillary muscle, double LAVV orifice, left ventricular hypoplasia, or isomeric atrial appendages were excluded, together with hearts unsuitable for correct anatomic measurements. Six had a partial, 2 an intermediate, and 26 a complete AVSD (Rastelli type A, 17; Rastelli type B, 1; Rastelli type C, 9).

Within the left ventricle of each specimen, we measured the inlet dimension, defined as the distance between the apex and the crux of the heart ${ }^{8}$ and the mural leaflet height (Fig 4, A). Lengths of the two major papillary muscles were measured from their bases (ie, the point at which papillary muscles fuse with the left ventricular free wall) to their heads (Fig 4, B). Lengths of primary chordae tendineae were measured from the head of their respective papillary muscles to their attachments on each respective bridging leaflet (ie, anterolateral papillary muscle to superior leaflet and posteromedial papillary muscle to inferior leaflet). Finally, we measured the interpapillary muscle (IPPM) distance, defined by the distance measured between the midpoints of the two major papillary muscles (midpoint was chosen to take into account the variations in diameter of the papillary muscles). ${ }^{24}$ Because the orientation of the major papillary muscles is nearly parallel to the plane of the muscular ventricular septum, ${ }^{8}$ the IPPM distance was previously found to be significantly correlated to the circumference of the mural leaflet. ${ }^{4,24,25}$ According to these findings, we postulated that the IPPM distance could reflect the mural leaflet angular size or, at least, its width. For standardization, all measurements were normalized with the value of the respective ventricular inlet dimension. ${ }^{24}$

Statistical analysis. Data are indicated as mean \pm SD. Anatomic measurements were stored and analyzed with a software package (Statview 5; Abacus Concepts, Inc, Berkeley, Calif). Correlations between continuous anatomic data were studied by linear regression analysis and a Pearson correlation coefficient. The probability for a significant correlation was calculated by a Fisher $r$ to $z$ transformation

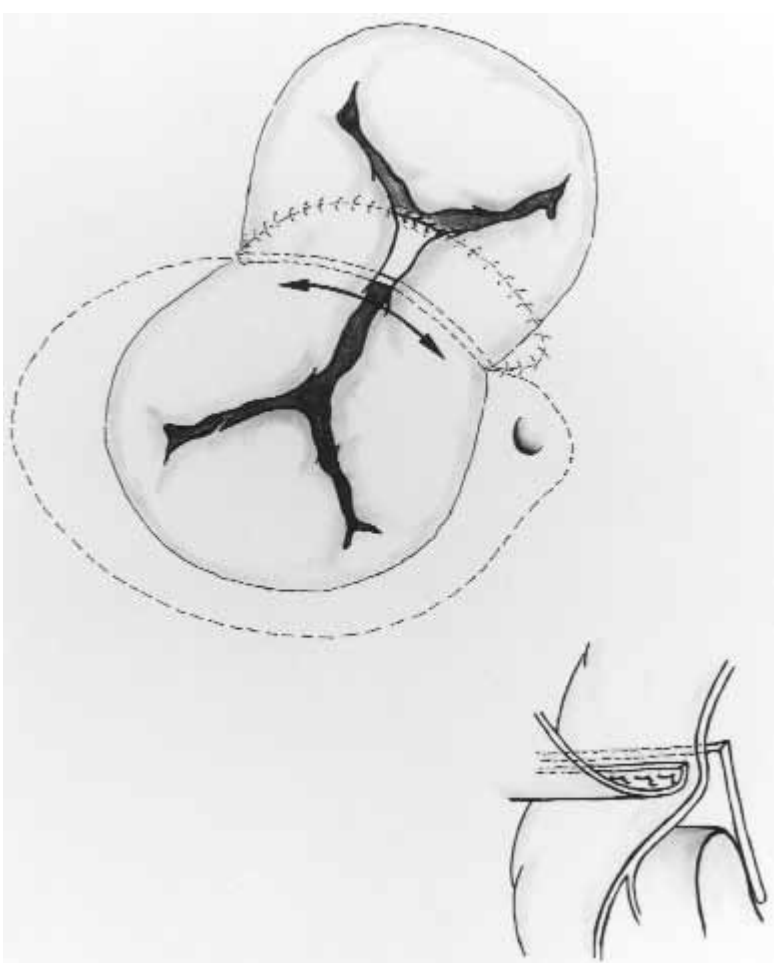

Fig 1. Operative procedure in complete AVSDs. Note that the base of the VSD patch is tailored in a concave shape (arrow) so as to fit exactly with valvular tissue, which is sandwiched between the VSD and ostium primum patches. Inset: Sandwiched patch technique.

allowing a probability level to be calculated for the null hypothesis that the correlation is equal to 0 .

\section{Results}

Hospital results. All patients underwent successful LAVV repair. No hospital deaths occurred. There were no instances of heart block, rhythm or conduction disturbance, subaortic stenosis, or residual intracardiac shunt. Median length of inotropic support was 24 hours (0-15 days). Median length of mechanical ventilation was 21 hours ( 2 hours-26 days). All patients had an uneventful postoperative course; the differences in intensive care unit stay were related only to the degree of preoperative pulmonary vascular resistance. There was no significant residual LAVV regurgitation or stenosis (Table II). Mean LAVV diastolic pressure gradient was $3.2 \pm 1.1 \mathrm{~mm} \mathrm{Hg}(1.4-4.5 \mathrm{~mm} \mathrm{Hg})$. Degree of LAVV regurgitation was none or trivial $(n=8)$ or mild $(n=2)$.

Follow-up time. Median follow-up was 72 months (59.2 \pm 10.4 months; range 6-91 months). There was 1 late death (3 years postoperatively, patient 6) unrelated to the repair, in a patient with a normally functioning 


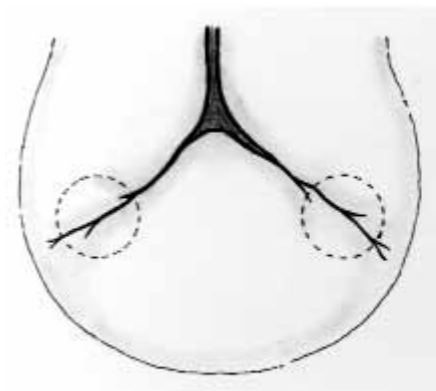

A

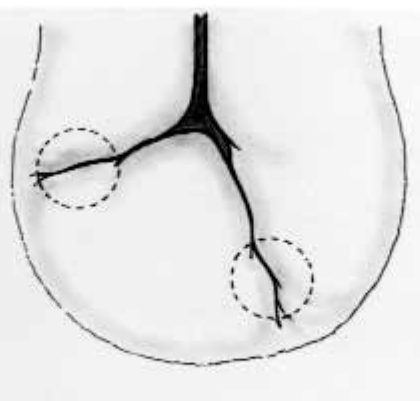

B

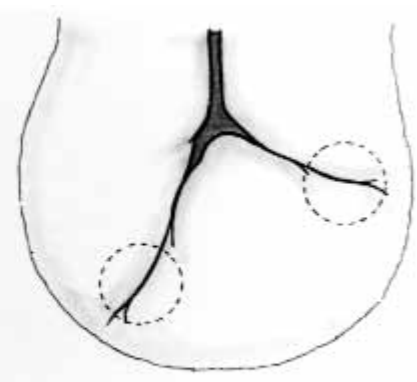

C

Fig 2. Intraoperative classification of the aspect of valvular tissue and position of the papillary muscles (dotted circle) according to Uemura and associates ${ }^{24}$ (surgical view). A, Parallel arrangement. B, Anterior displacement. C, Posterior displacement.

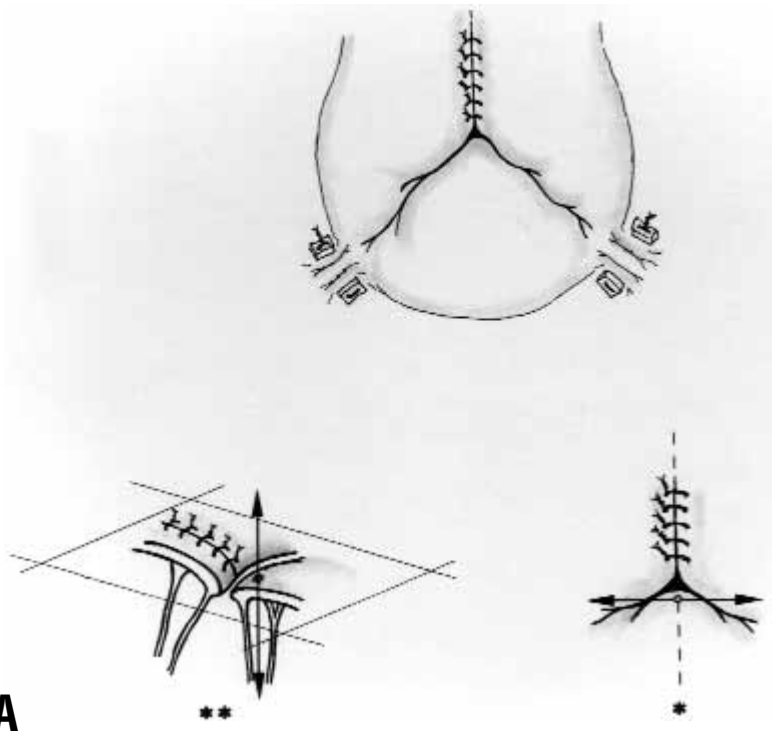

A

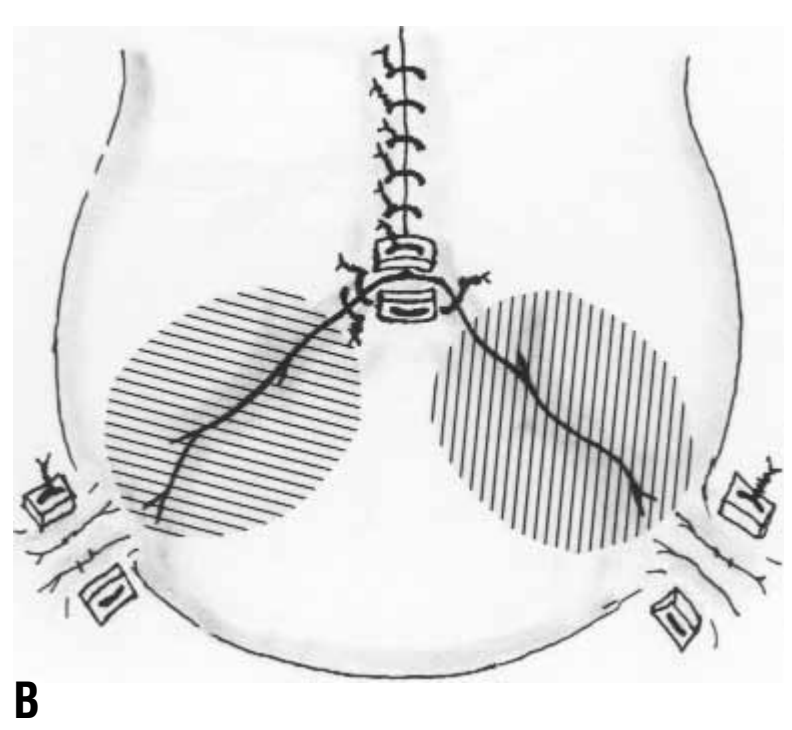

B

Fig 3. Surgically created double-orifice LAVV. A, Mechanism of the residual regurgitation: defect in apposition to the top edge of the mural leaflet either by a lateral displacement/central malalignment $(*)$ or an anteroposterior $(* *)$ defect of coaptation. B, Surgical creation of the double orifice by interrupted $(n=8)$ or interrupted and mattress sutures $(\mathrm{n}=2)$ with commissural annuloplasties.

LAVV. Death was due to pulmonary hypertension followed by the development of pulmonary vascular obstructive disease.

The degree of LAVV regurgitation did not increase over time except in 1 patient (patient 7) who lately progressed from mild to moderate regurgitation (Table II). At reoperation (performed abroad), there was no evidence of disruption of the repair, but rolling and thickening of the valvular tissue edges associated with annular dilatation led to valve replacement.

Mean LAVV diastolic gradient $(3.8 \pm 2.9 \mathrm{~mm} \mathrm{Hg})$ was not significantly different from the immediate postoperative status $(P=.47)$. However, the distribu- tion of gradients and surfaces was wide, from 1.5 to $11.2 \mathrm{~mm} \mathrm{Hg}$ and from 1.15 to $2.8 \mathrm{~cm}^{2}(2.06 \pm 0.58$ $\mathrm{cm}^{2} ; 8$ measures available) (Table II), although these procedures were performed in each case only when a large mural leaflet was present. One patient (patient 9) had an early increase in the mean diastolic gradient (from 4.5 to $11.2 \mathrm{~mm} \mathrm{Hg}$ ). However, his clinical status improved without medical treatment (New York Heart Association functional class II) and with a normal pulmonary pressure (echographic assessment).

The 7 remaining patients are asymptomatic without medical treatment and with a mean LAVV diastolic gradient less than $6 \mathrm{~mm} \mathrm{Hg}$. The patient with an inter- 

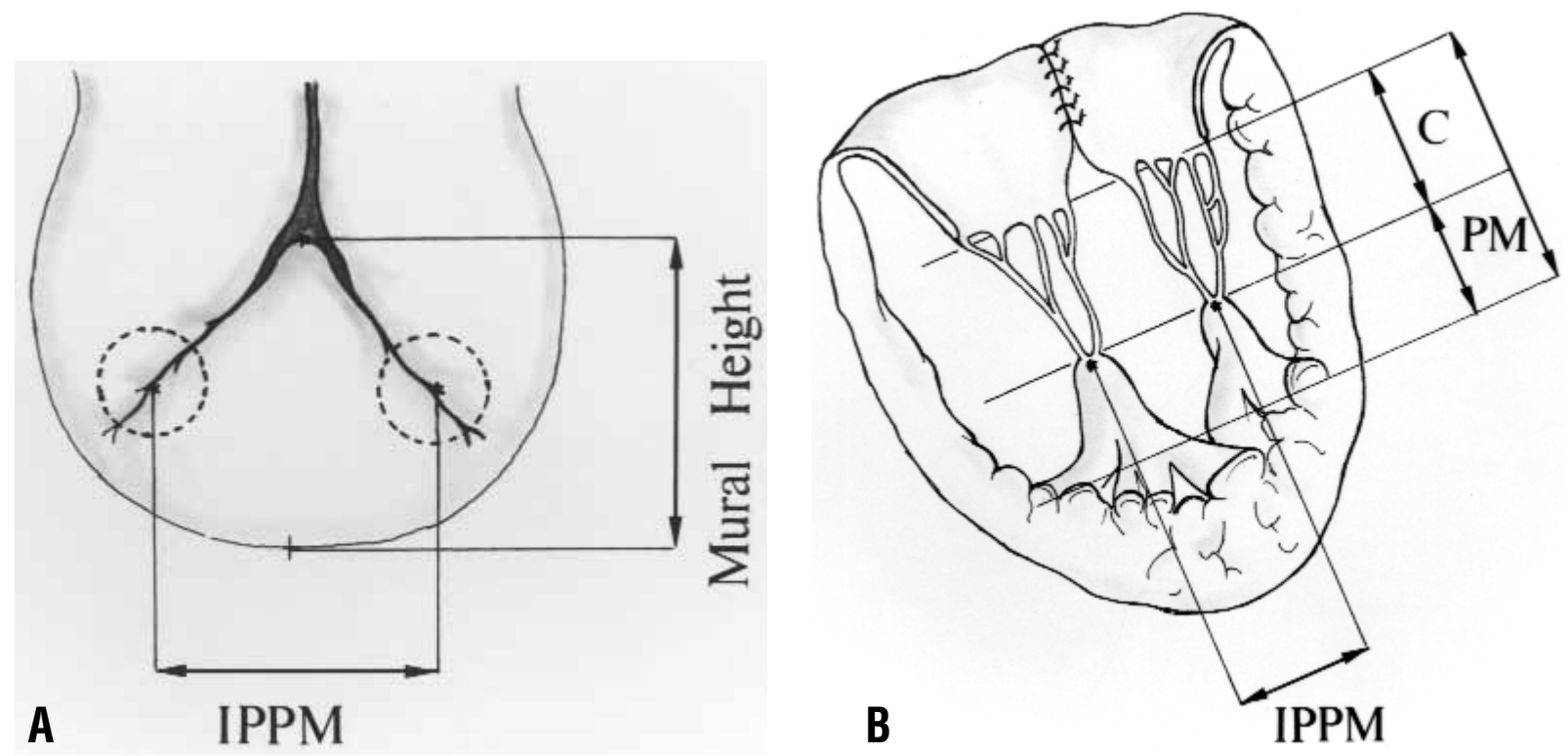

Fig 4. Measurements of pathologic specimens. A, Shape of the mural leaflet. Interpapillary muscle distance $(I P P M)$ and mural leaflet height. B, Subvalvular apparatus. Length of each chorda $(C)$ and papillary muscle $(P M)$ of anterolateral and posteromedial subvalvular apparatus.

mediate AVSD (patient 3), operated on with an isosystemic pulmonary artery pressure, had a normal systolic pulmonary artery pressure at late follow-up.

Bidimensional echocardiographic studies in the parasternal axis view showed an LAVV double-orifice aspect in all patients except in one for whom this information was not available. One orifice was considered nonfunctional in 2 patients ( 1 with a posterior [anterior functional orifice] and 1 with an anterior displacement of papillary muscles [posterior functional orifice]). A representative view is presented in Fig 5. The two-cavity apical long-axis echocardiographic view seemed to be the best method to assess the function of a doubleorifice repair, as shown in Fig 6. The patient with an early moderate stenosis had short chordae tendineae at the level of the two papillary muscles, predominantly at the level of posteromedial insertions. These echographic views suggested that the subvalvular apparatus might be essential in determining the LAVV diastolic flow characteristics.

Pathologic specimens. First, there was a positive correlation between the IPPM and mural leaflet height (mural leaflet height $=0.48 \cdot$ IPPM $+0.1, r=0.53$, $P=.001 ;$ Fig $7, A$ ).

Second, a weak but significant correlation existed between the IPPM and either the anterolateral $(r=0.45$, $P<.01)$ or posteromedial $(r=0.42, P=.01)$ subvalvular apparatus lengths ( papillary muscles plus lengths of the chordae tendineae) (Fig 7, B). A significant but weaker correlation existed between the mural leaflet height and anterolateral subvalvular apparatus length $(r=0.40, P<.02)$. Conversely, no correlation was detected between the mural leaflet height and the posteromedial subvalvular apparatus length $(r=0.18$, $P=.31$ ). The posteromedial subvalvular apparatus was significantly shorter than the anterolateral subvalvular apparatus $(P<.001)$.

Third, no correlation was detected between the IPPM distance and length of the chordae tendineae depending on either the anterolateral $(r=0.31, P=.08)$ or posteromedial $(r=0.18, P=.21)$ papillary muscles. There was no correlation between the height of the mural leaflet and the lengths of the chordae tendineae depending either on the anterolateral $(r=0.33$, $P=.053)$ or posteromedial papillary muscles $(r=0.28$, $P=.11$ ) (Fig 7, C). Therefore, lengths of the chordae tendineae were unrelated to the shape of the mural leaflet in AVSD. Thus, the distance between the head of the papillary muscles and the valvular orifices was highly variable, as could be anticipated from Fig 6 . Thus, although the orifice sizes at the valvular level seemed geometrically predictable, the subvalvular aspects added another variable that should be independently assessed.

Finally, Fig 8 shows two pathologic specimens of similar normalized shapes (IPPM and mural leaflet 


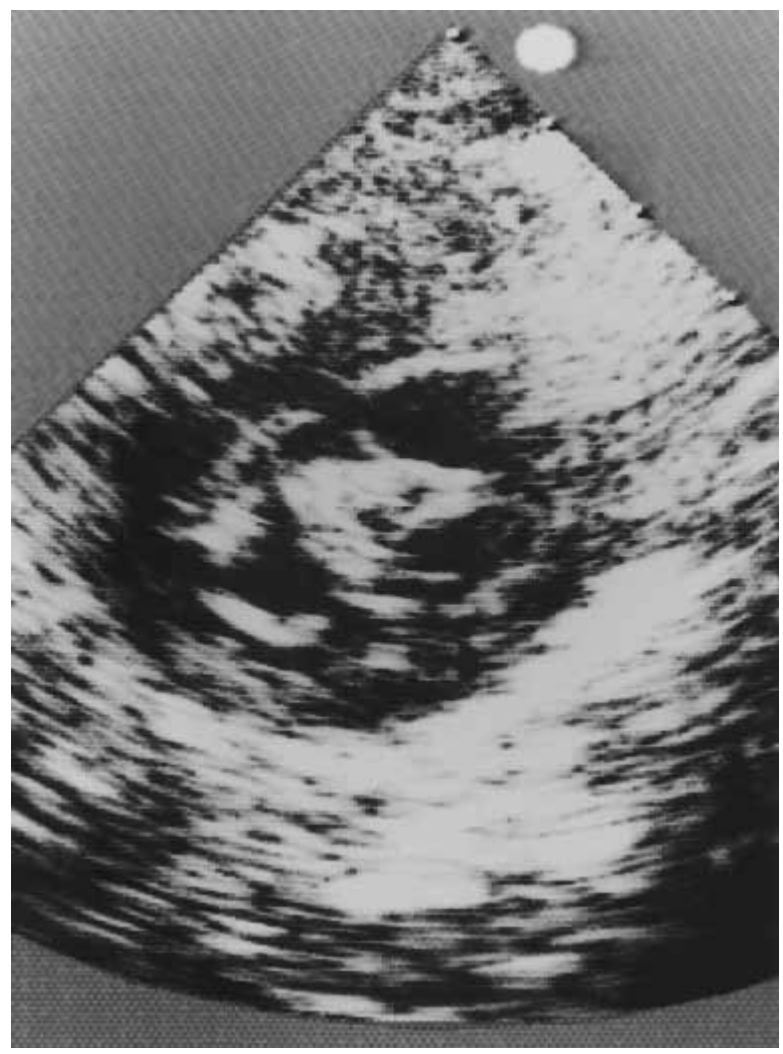

Fig 5. Representative postoperative bidimensional echocardiographic aspect in parasternal short-axis view (patient 5).

height), but with two different aspects of the subvalvular apparatus, one suitable (Fig 8, $A$ ) and one unsuitable (Fig 8, B) for a double-orifice repair. The normally wide IPPM distance between the anterolateral and posteromedial papillary muscles forms the major component of the LAVV orifice in the event the cleft is closed. ${ }^{25}$ When a double-orifice repair is performed, our procedure results in a so-called "type $2 \mathrm{~B}$ " potentially parachute LAVV. ${ }^{25}$ This is the reason that chordae tendineae must be long enough for the head of the papillary muscle to be as far as possible from the valvular orifices. However, the situation is certainly more complex, because (1) the aspect of the chordae themselves should be taken into consideration (thickening and/or convergence $)^{7}$ and (2) the diameter of the papillary muscle increases when its length increases, ${ }^{24}$ which constitutes another potential factor to create a significant diastolic restriction.

\section{Discussion}

The surgically created double-orifice repair has allowed us to obtain satisfactory clinical results in patients in whom these procedures were used as a valve-sparing repair. Even if we have not performed echocardiographic exercise testing, patients are usually asymptomatic, leading a normal life without medical treatment. However, significant concern remains regarding the risk of creating an LAVV stenosis. Despite the fact that this technique was always applied in patients with a large mural leaflet angular size, a wide range of LAVV diastolic gradients could be observed, with one instance of early significant stenosis. Echographic studies suggested that the functional characteristics of the subvalvular apparatus might be essential in determining the diastolic LAVV flow. Anatomic studies emphasized that mural leaflet shape and subvalvular apparatus characteristics are important determinants. Actually, the mural leaflet angular size (greater than $120^{\circ}$ ) has become an accepted criterion to determine whether the cleft could be closed. ${ }^{23}$ However, to perform a double-orifice repair implies looking at a second criterion, which must be the lengths of the chordae tendineae together with the position of the papillary muscles according to the classification of Uemura and associates. ${ }^{24}$

Unusual morphology of the LAVV is more common in the setting of separate orifices as compared with hearts with a common valve orifice ${ }^{4,5,10}$ Furthermore, delay in repair may add adverse dystrophic degenerative structural changes to the LAVV, such as annular dilatation or acquired elongation of the chordae tendineae (ie, posterior leaflet prolapse, thickening of chordae, rolling of valvular tissue), demonstrating an increase in severity with age. ${ }^{6,7}$ It stimulates another argument in favor of early repair in infancy. Our patient population reflected these aspects, because primary repairs were performed in cases of separate orifices and redo operations (or after a pulmonary artery banding) in patients with a common orifice.

The grade of LAVV regurgitation was stable over time. The only regurgitation appeared recently, after an uneventful 6-year period, disclosing a rapid deterioration in the valve status. At reoperation, there was no double-orifice repair disruption, but mainly an annular dilatation. It is likely that bilateral commissural annuloplasty during the initial repair in this patient was insufficient and an annular remodeling should have been necessary. Thus, performing a double-orifice repair does not preclude the use of conventional additional procedures.

The procedure did not result in significant postoperative stenosis, although there was a large range of LAVV diastolic gradients, stable for many years, meaning that there is a potential for growth in the area that 


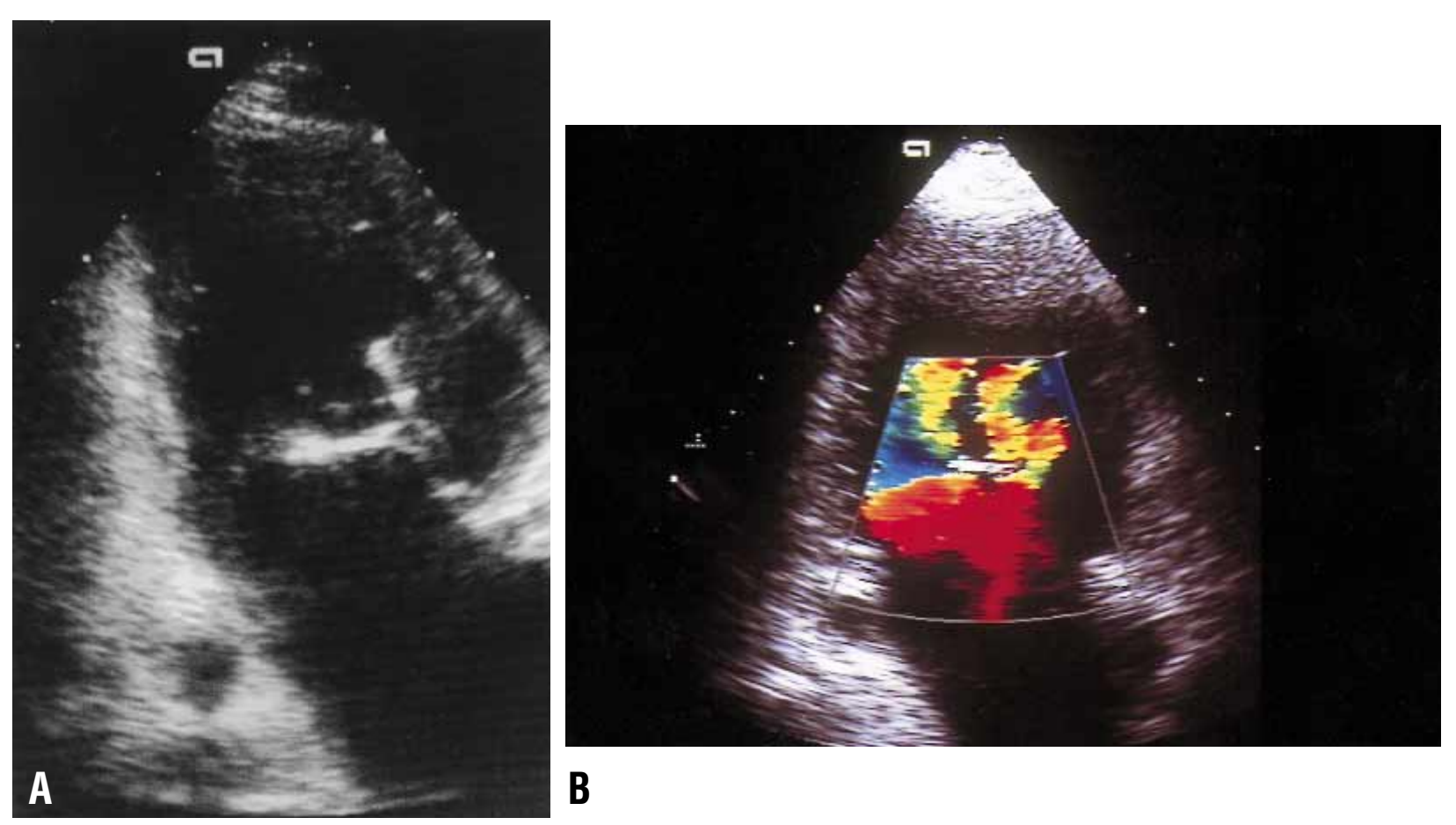

Fig 6. Representative postoperative echocardiographic aspect in apical two-cavity long-axis views (patient 2). A, Bidimensional view. B, Diastolic color-coded flow showing an unrestricted flow through the inferior orifice and a restricted flow through the superior orifice, divided in two parts by the presence of the head of the anterolateral papillary muscle.

was repaired. These results may not be explained by the size of the mural leaflet (always large angular size in this series) and consequently by the size of the two orifices, but by the aspect of the subvalvular apparatus as suggested on the postoperative echocardiographic views (Fig 6, B). The patient who had an early moderate stenosis has a bilateral unfavorable anatomy of the subvalvular apparatus that was not recognized during the operation. However, the reasons for early stenosis (without immediate postoperative stenosis) remain speculative. One possibility is an increase in systemic blood flow. A second, more convincing possibility is a decrease in the left ventricular size, which may bring the two papillary muscles in a more prominent position toward the orifices or increase the diameters of the papillary muscles, unmasking the potential for a "double parachute mitral valve."

The difficulty in performing a quantitative retrospective echocardiographic analysis of LAVV subvalvular apparatus led us to perform an anatomic study in AVSD with two distinct papillary muscles. Although we studied hearts with common or separate orifices, it has been previously reported that no significant differences were found in the angular size of either LAVV leaflets between hearts with a common orifice and those with separate orifices. ${ }^{4}$ Conversely to Penkoske and colleagues, ${ }^{8}$ we found that the two subvalvular apparatus were not equal in size (the anterolateral subvalvular apparatus being longer). Anatomic studies demonstrated a high variability in chordal length, which may explain the large range of LAVV diastolic gradients. Moreover, we have to disagree with Draulans-Noë, Wenink, and Quaegebeur ${ }^{26}$ that the size of the tension apparatus is related to the degree of development of the mural leaflet. This is true for the total length of the subvalvular apparatus but incorrect for the length of chordae tendineae, at least in pathologic specimens with two distinct papillary muscles.

Thus, the mural leaflet angular size is too restrictive a criterion for determining the feasibility of double-orifice repair. Chordal lengths at each subvalvular apparatus level may play a determinant role because they were not correlated to the mural leaflet shape and because they could produce an arrangement comparable with a double parachute mitral valve. ${ }^{27}$ At worst, this anatomic feature has been previously emphasized by Warnes and Somerville ${ }^{28}$ : "the orifices [of native double-orifice AVSD] can be small with tethered 
A

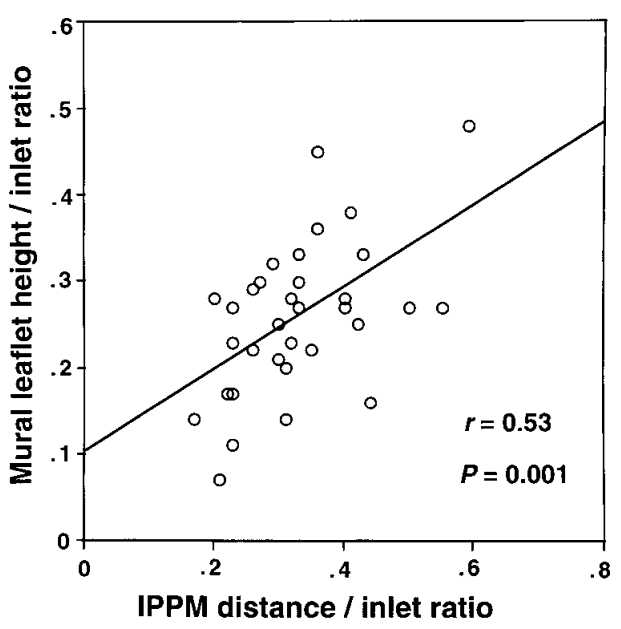

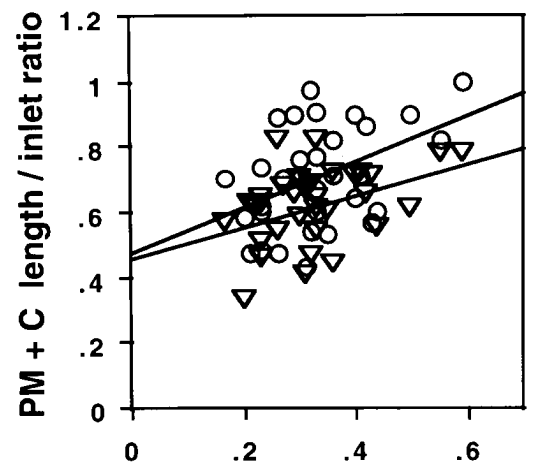

IPPM distance / inlet ratio

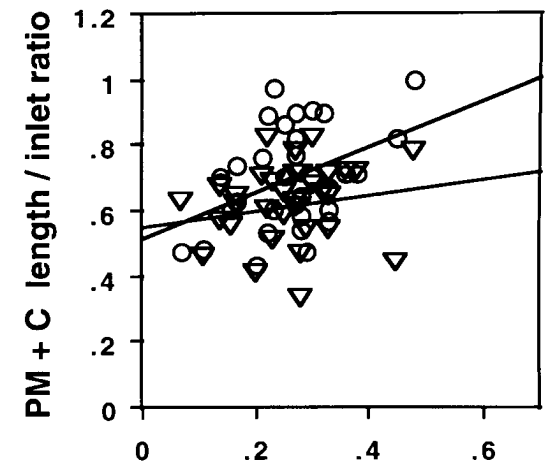

Mural leaflet height / inlet ratio

B

$\circ$ anterolateral papillary muscle $\quad \nabla$ posteromedial papillary muscle

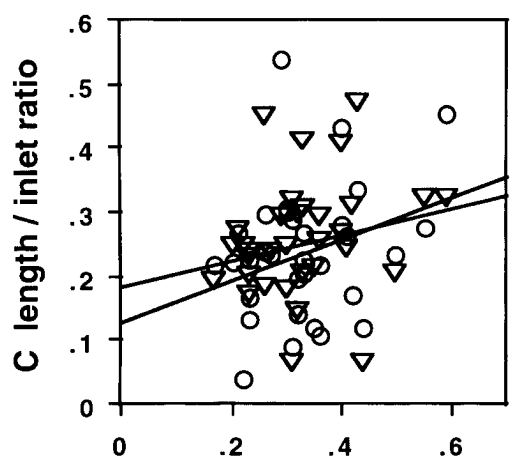

IPPM distance / inlet ratio

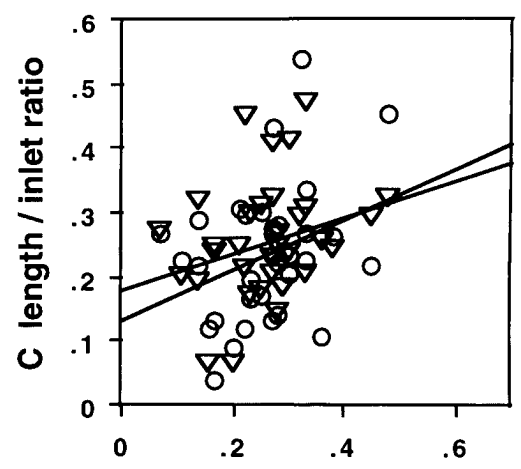

Mural leaflet height / inlet ratio

C

$$
\begin{array}{|llll}
\hline \circ & \text { anterolateral chordae } & \nabla & \text { posteromedial chordae }
\end{array}
$$

Fig 7. Anatomic study on pathologic specimens. A, Scatterplot showing a direct significant correlation between the width (estimated by the interpapillary muscles distance) and height of the mural leaflet. B, Bivariate plots showing relationships between the width or height of the mural leaflet and the total length of the subvalvular apparatus (papillary muscle plus chordae). C, Bivariate plots showing no correlation between the width or height of the mural leaflet and the length of chordae. (See text for statistical significance.) 

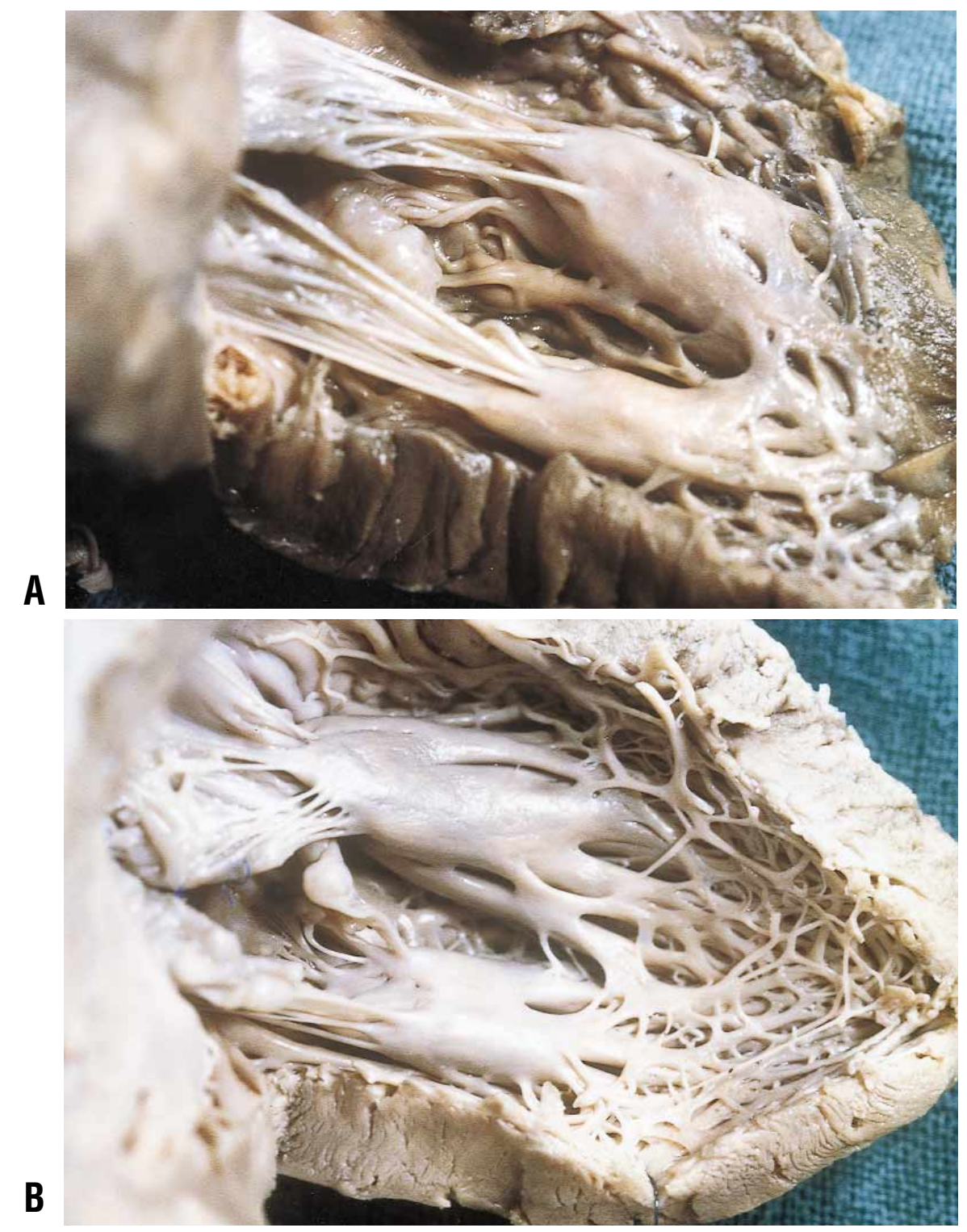

Fig 8. Pathologic specimens with similar interpapillary muscle distance and mural leaflet height/inlet ratio (ie, mural leaflet shapes) but with two different aspects of the subvalvular apparatus and chordal lengths. A, Long chordae, in which double-orifice repair seems feasible, if necessary. B, Short chordae, with the risk of creation of a double parachute mitral valve in the event a double-orifice repair being used.

chordal attachments causing LAVV obstruction." This emphasizes again the necessity for the chordae tendineae to be long enough in the event a surgically created double-orifice repair is considered. Furthermore, we paraphrase the conclusions of Baño-Rodrigo and colleagues ${ }^{29}$ : the key to the diagnostic and surgical understanding of the double-orifice LAVV is the underlying subvalvular apparatus. Furthermore, they described an inverse relationship between lengths of the chordae tendineae and leaflet tissue developments leading to the creation of a chordal ring: the larger the chordal ring, the larger the LAVV orifice.

Finally, two additional features may be of importance: (1) the position and (2) the diameter of the two papillary muscles. A parallel arrangement may lead to symmetric orifices, a deviation of the papillary muscles to asymmetric orifices. Whether or not this particular point has an importance is a subject of speculation 
because low diastolic gradients were observed in our series when only one functional orifice was present. A 3-dimensional computational study demonstrated that the resultant surface was more important than the actual aspect of each orifice, symmetric or asymmetric, because hemodynamic behavior of a double-orifice mitral valve does not differ from that of a physiologic valve of the same total area. ${ }^{19}$ Concerning the papillary muscle diameters, the shorter the chordae, the longer the papillary muscles and consequently the larger the diameter of the papillary muscles, ${ }^{24}$ which in these conditions will constitute a more important obstacle, emphasizing again the necessity for chordae tendineae to be long enough.

The valvular coaptation is a subtle mechanism in AVSD because of the central triangular shape of the leaflets, leading to an increased risk of LAVV regurgitation in the presence of a large mural leaflet angular size and consequently a large height, as demonstrated in our anatomic study, because this anatomic aspect may increase the stress onto the subvalvular apparatus. Theoretically, two mechanisms could lead to a central regurgitation (apart from annular dilatation and cleft dysfunction): (1) a lateral displacement with mural leaflet malalignment and (2) an anteroposterior defect in coaptation. Although it could be considered a speculation, this latter mechanism could be related to a restriction of the valvular tissue at the cleft level, eventually favored by its closure, or to a prolapse of the top edge of the mural leaflet, which is known to be a frequent acquired degenerative lesion (Fig 3, $A$ ).

Could these valves be repaired without a double-orifice repair technique? The cleft closure was judged necessary in each patient. Additional procedures were performed to avoid the use of a surgically created double-orifice repair. In fact, the double orifice was an indirect repair. It would have been more advisable to correct the primary mechanism. Such an operation was attempted in adults and judged unfeasible in infants and children. Perhaps the ideal procedure would be a standard repair, a postoperative transesophageal echocardiogram and an immediate redo repair with a doubleorifice repair if necessary and feasible. However, a more efficient annuloplasty reducing the mural leaflet angular size (but leading to a reduced IPPM distance $)^{3,16}$ may not have been efficient in case of mural leaflet malalignment. Use of chordal transfer, patch augmentation of the superior and inferior bridging leaflets, could have been performed. ${ }^{17}$ An alternative may be a triple-orifice repair as previously described by Alfieri and associates (unpublished data, 1988; cleft left unsutured and triple central suture discussed in ref- erence 5). One such operation, not included in the present study, was performed in our entire series, in the presence of a severe residual LAVV regurgitation associated with a small mural leaflet and a long cleft. There was a moderate residual regurgitation, but unfortunately this patient was lost to follow-up.

The literature reflects a wide variation of attitudes concerning the necessity of closing the cleft when repairing a native double orifice. This anatomic feature is uniformly recognized as a risk factor for postoperative mortality, ${ }^{1,2,6,17}$ except in the study of Abbruzzese and coworkers. ${ }^{5}$ Although the comparison with native double orifices in AVSD seems inevitable, it represents a different setting: First, a small mural leaflet is present in the majority of native double orifices, sometimes associated with varying degrees of left ventricular hypoplasia. ${ }^{6,17,26}$ Second, a parachute appearance of the subvalvular apparatus may be present at the level of the minor orifice. ${ }^{26}$ Third, these malformations are characterized by convergence of chordal insertions into a papillary muscle, creating the possibility for a parachute mitral valve and rendering the patients poor candidates for cleft closure; in other words, when there is a cleft main orifice and a noncleft accessory orifice, cleft closure transforms the potentiality of a major orifice into an actual parachute LAVV. ${ }^{25,26}$ Finally, the frequency of significant postoperative regurgitations is increased as a result of the absence of cleft closure. However, it is certainly not our purpose to promote the idea that the cleft should be closed in native double orifice. Regarding this problem, it is likely that the two criteria (ie, angular size of the mural leaflet and length of the chordae tendineae) must also be observed. Some authors militate against cleft closure because of the obvious risk of stenosis in doubleorifice AVSD. ${ }^{26}$ Other surgeons closed one of the orifices and left the cleft partially open. ${ }^{30,31}$ More frequently, the decision to close the cleft has been performed on an individual basis, depending on its length, degree of incompetence, and size of the mural leaflet angle. ${ }^{1,32}$ In such situations, the extension of the cleft suture is limited by the size of the valve opening, which is measured with Hegar dilators. In the report by Ilbawi and associates, ${ }^{6}$ who used this approach, only 1 patient had a significant mitral stenosis. Cleft closure has been performed on 6 of 11 patients described by Warnes and Somerville, ${ }^{28}$ with one resulting stenosis. Lee and colleagues ${ }^{31}$ suggested that orifice sizes of $65 \%$ to $70 \%$ of normal were uniformly well tolerated. Finally, some authors advocated cleft closure without postoperative evidence of stenosis. ${ }^{27,33} \mathrm{In}$ our entire group of patients, cleft closure has been performed on 10 of 13 patients with native double orifice without causing significant 
stenosis (LAVV diastolic gradient always $<6 \mathrm{~mm} \mathrm{Hg}$ ). This surely indicates that the combined orifice area of a double-orifice LAVV is sufficiently large to avoid a significant stenosis when the anatomic aspects are favorable (Fig 6, $A$ ).

The following natural and important comparison results from the "classic" edge-to-edge Alfieri technique. ${ }^{18,19}$ This method is promoted as a reliable alternative repair with predictable results. The mitral valve area was $2.9 \pm 0.57 \mathrm{~cm}^{2}$ with no significant transvalvular gradient. A concomitant mitral annuloplasty did not reduce the mitral surface at rest. When this technique is applied to ischemic mitral regurgitation (without annular dilatation), the mean surface is $2.1 \pm 0.3 \mathrm{~cm}^{2}$ and the mean gradient is $6 \pm 2 \mathrm{~mm} \mathrm{Hg} .{ }^{20}$ Nevertheless, a surgically created double-orifice repair in AVSD must not be compared with the edge-to-edge technique because (1) it is not an alternative to a standard repair but a valvesparing procedure, (2) diastolic LAVV gradients are higher and the surfaces lower, (3) the results demonstrated a wide variation, and (4) the criteria of feasibility are retrospectively determined. Therefore, the double-orifice repair cannot be considered a standard alternative procedure, but as an exception rather than a rule, whose safety remains to be assessed.

In conclusion, the surgically created double-orifice repair must be used with caution. It does not preclude the use of classic additional procedures of LAVV repair. It could be performed (1) in the presence of a large mural leaflet angular size and (2) if there is a suitable aspect of the subvalvular apparatus, that is, chordal lengths sufficient to move away the heads of the papillary muscles and associated with a lower diameter of the papillary muscles. The use of this procedure on other patients remains under evaluation and must be applied only as a valve-sparing procedure with an intraoperative transesophageal echocardiogram. ${ }^{11}$

\section{REFERENCES}

1. Bando K, Turrentine MW, Sun K, Sharp TG, Ensing GJ, Miller AP, et al. Surgical management of complete atrioventricular septal defects. J Thorac Cardiovasc Surg 1995;110:1543-54.

2. Hanley FL, Fenton KN, Jonas RA, Mayer JE, Cook NR, Wernovsky G, et al. Surgical repair of complete atrioventricular canal defects in infancy: twenty-year trend. J Thorac Cardiovasc Surg 1993;106:387-97.

3. Meijboom EJ, Wyse RKH, Ebels T, Deanfield JE, Quaegebeur $\mathrm{JM}$, Anderson RH, et al. Doppler mapping of postoperative left atrioventricular valve regurgitation. Circulation 1988;77:311-5.

4. Ebels T, Anderson RH, Devine WA, Debich DE, Penkoske PA, Zuberbuhler JR. Anomalies of the left atrioventricular valve and related ventricular septal morphology in atrioventricular septal defects. J Thorac Cardiovasc Surg 1990;99:299-307.

5. Abbruzzese PA, Napoleone A, Bini RM, Annechino FP, Merlo
M, Parenzan L. Late left atrioventricular valve insufficiency after repair of partial atrioventricular septal defects: anatomical and surgical determinants. Ann Thorac Surg 1990;49:111-4.

6. Ilbawi MN, Idriss FS, DeLeon SY, Riggs TW, Muster AJ, Berry TE, et al. Unusual mitral valve abnormalities complicating surgical repair of endocardial cushion defects. J Thorac Cardiovasc Surg 1983;85:697-704.

7. Piccoli GP, Ho SY, Wilkinson JL, Macartney FJ, Gerlis LM, Anderson RH. Left-sided obstructive lesions in atrioventricular septal defects. J Thorac Cardiovasc Surg 1982;83:453-60.

8. Penkoske PA, Neches WH, Anderson RH, Zuberbuhler JR. Further observations on the morphology of atrioventricular septal defects. J Thorac Cardiovasc Surg 1985;90:611-22.

9. Michielon G, Stellin G, Rizzoli G, Milanesi O, Rubino M, Moreolo GS, et al. Left atrioventricular valve incompetence after repair of common atrioventricular canal defects. Ann Thorac Surg 1995;60:S604-9.

10. Baufreton C, Journois D, Leca F, Khoury W, Tamisier D, Vouhé P. Ten-year experience with surgical treatment of partial atrioventricular septal defect: risk factors in the early postoperative period. J Thorac Cardiovasc Surg 1996;112:14-20.

11. Backer CL, Mavroudis C, Alboliras ET, Zales VR. Repair of complete atrioventricular canal defects: results with the twopatch technique. Ann Thorac Surg 1995;60:530-7.

12. Weintraub RG, Brawn WJ, Venables AW, Mee RBB. Two-patch repair of complete atrioventricular septal defect in the first year of life: results and sequential assessment of atrioventricular valve function. J Thorac Cardiovasc Surg 1990;99:320-6.

13. Kirklin JW, Barratt-Boyes BG. Atrioventricular canal defect. In: Kirklin JW, Barratt-Boyes BG, editors. Cardiac surgery. 2nd ed. New York: Churchill Livingstone; 1993. p. 693-748.

14. Carpentier A. Surgical anatomy and management of the mitral component of atrioventricular canal defects. In: Anderson RH, Shinebourne EA, editors. Pediatric cardiology. London: Churchill Livingston; 1978. p. 477-90.

15. Capouya ER, Laks H, Drinkwater DC Jr, Pearl JM, Milgalter E. Management of the left atrioventricular valve in the repair of complete atrioventricular septal defects. J Thorac Cardiovasc Surg 1992;104:196-203.

16. Miyamura H, Eguchi S, Watanabe H, Kanazawa H, Suguwara M, Tatebe S, et al. Total circular annuloplasty with absorbable suture for the repair of left atrioventricular valve regurgitation in atrioventricular septal defect. J Thorac Cardiovasc Surg 1994;107:1428-31.

17. Najm HK, Coles JG, Endo M, Stephens D, Rebeyka IM, Williams WG, et al. Complete atrioventricular septal defects: results of repair, risk factors, and freedom from reoperation. Circulation 1997;96(Suppl):II-311-5.

18. Maisano F, Torracca L, Oppizzi M, Stefano PL, D’Addario G, La Canna G, et al. The edge-to-edge technique: a simplified method to correct mitral insufficiency. Eur J Cardiothorac Surg 1998;15:240-6.

19. Maisano F, Redaelli A, Pennati G, Fumero R, Torracca L, Alfieri $O$. The hemodynamic effects of double-orifice valve repair for mitral regurgitation: a 3D computational model. Eur $\mathrm{J}$ CardioThorac Surg 1999;15:419-25.

20. Umaña JP, Salehizadeh B, DeRose JJ Jr, Nahar T, Lotvin A, Homma S, et al. "Bow-tie" mitral valve repair: an adjuvant technique for ischemic mitral regurgitation. Ann Thorac Surg 1998;66:1640-6

21. Rastelli G, Kirklin JW, Titus JL. Anatomic observations on com- 
plete form of persistent common atrioventricular canal with special reference to atrioventricular valves. Mayo Clin Proc 1966;41:296-308.

22. Bharati S, Lev M, McAllister HA Jr, Kirklin JW. Surgical anatomy of the atrioventricular valve in the intermediate type of common atrioventricular orifice. J Thorac Cardiovasc Surg 1980;79:884-9.

23. Abbruzzese PA, Livermore J, Sunderland CO, Nunley DL, Issenberg $\mathrm{H}$, Khonsari $\mathrm{S}$, et al. Mitral repair in complete atrioventricular canal: ease of correction in early infancy. $\mathrm{J}$ Thorac Cardiovasc Surg 1983;85:388-95.

24. Uemura H, Anderson RH, Ho SY, Devine WA, Neches WH, Smith A, et al. Left ventricular structures in atrioventricular septal defect associated with isomerism of atrial appendages compared with similar features with usual atrial arrangement. J Thorac Cardiovasc Surg 1995;110:445-52.

25. David I, Castaneda AR, Van Praagh R. Potentially parachute mitral valve in common atrioventricular canal. J Thorac Cardiovasc Surg 1982;84:178-86.

26. Draulans-Noë HAY, Wenink ACG, Quaegebeur J. Single papillary muscle ("parachute valve") and double-orifice left ventricle in atrioventricular septal defect convergence of chordal attachment: surgical anatomy and results of surgery. Pediatr Cardiol 1990;11:29-35.

27. Cooke RA, Chambers JB, Curry PVL. Doppler echocardiography of double orifice of the left atrioventricular valve in atrioventricular septal defect. Int J Cardiol 1991;32:254-6.

28. Warnes C, Somerville J. Double mitral valve orifice in atrioventricular defects. Br Heart J 1983;49:59-64.

29. Baño-Rodrigo A, Van Praagh S, Trowitzsch E, Van Praagh R. Double-orifice mitral valve: a study of 27 postmortem cases with developmental, diagnostic and surgical considerations. Am J Cardiol 1988;61:152-60.

30. Brieger DB, Ward C, Cooper SG, Nunn R, Cartmill TB, Sholler GF. Double orifice left atrioventricular valve-diagnosis and management of an unexpected lesion. Cardiol Young 1995;5:26771.

31. Lee CN, Danielson GK, Schaff HV, Puga FJ, Mair DD. Surgical treatment of double-orifice mitral valve in atrioventricular canal defects. J Thorac Cardiovasc Surg 1985;90:700-5.

32. Najm HK, Williams WG, Chuaratanaphong S, Watzka SB, Coles JG, Freedom RM. Primum atrial septal defect in children: early results, risk factors, and freedom from reoperation. Ann Thorac Surg 1998;66:829-35.

33. Alexi-Meskishvili V, Ishino K, Dähnert I, Uhlemann F, Weng Y, Lange PE, et al. Correction of complete atrioventricular septal defects with the double-patch technique and cleft closure. Ann Thorac Surg 1996;62:519-25.

\section{Discussion}

Dr Constantine Mavroudis (Chicago, Ill). Dr Macé and his coworkers are to be congratulated on an extraordinary clinical series and a classic anatomic study worthy of great praise. They have correctly identified LAVV dysfunction as a significant long-term risk factor for patients with atrioventricular canal. Their thoughtful approach to the repair of the incompetent LAVV is clearly superior to prosthetic valve replacement, which is associated with a dismal outcome in these young patients. Their double-orifice valve repair is a variation on a theme that has been advocated by Umaña, Alfieri, Maisano, and others.
Besides the excellent clinical results that they achieved, the authors performed a very nice anatomic study to determine those patients who are the best candidates for this double-orifice valve repair based on IPPM distance and position. The angular mural leaflet size was important, as was the chordal height. This anatomic study, which is part of the manuscript, is a significant contribution in itself and more clearly defines the indications that this repair can be used.

I have two questions for the authors.

In the few patients with this problem whom we have treated, we chose to augment the anterior leaflet with a pericardial patch, thereby advancing the anterior leaflet to provide better coaptation with the mural leaflet. Do you think that is a reasonable approach, especially since some of these patients will have subaortic stenosis or may have subaortic stenosis in the future?

I noted in your manuscript that this repair resulted in valve distortion in 1 patient, and you abandoned this operation. However, you put the pericardial patch only on the left side and did not include it all the way for the entire length of the anterior leaflet. Would you comment on that? Also, would you contrast and compare these two techniques in support of your thesis?

Oftentimes operations for an LAVV insufficiency after complete atrioventricular canal reveal a disrupted anterior cleft. In fact, when one reoperates on these patients, all one sees is a disrupted anterior cleft. We have had very good results, as have others, by just suturing this anterior cleft and leaving the repair as is. Would you ever leave it that way instead of doing your two-orifice repair?

Dr Macé. Thank you very much for your comments, Dr Mavroudis.

With regard to leaflet augmentation as an alternative, in our opinion most of the patients will have good LAVV function after undergoing standard operative procedures (ie, cleft closure and eventually commissural annuloplasty). However, two situations will be associated with an increased risk for residual LAVV regurgitation.

The first is the presence of a small mural leaflet with papillary muscles tethering the valvular tissue. In that situation, it is probably a good option to perform a leaflet augmentation to improve the central valvular coaptation.

Conversely, the second risk factor for regurgitation may be related to acquired degenerative changes inducing chordal elongation. In the presence of a leaflet prolapse, the only possible response is not to perform a leaflet augmentation, but to obtain a real correction of the mechanism responsible for the prolapse. In fact, we can obtain a satisfactory repair using an indirect procedure (ie, a double-orifice repair), because it was not judged easy or feasible to perform a chordal shortening and we prefer to anchor the top edge of the mural leaflet to the cleft. Thus, I have to agree again that this procedure is an indirect repair, but in patients for whom elongation of primary chordae was responsible for the residual regurgitation, it was judged that leaflet augmentation could not be adequate.

Concerning the patient with a valvular distortion, I agree that a good alternative might have been to perform a complete takedown of the repair at the level of both superior and inferior bridging leaflets and to do a large leaflet implantation, as previously described by Dr Williams' 
team. It is not my purpose to say that there were no other possibilities for repairing the LAVV of the patients presented in this clinical series. The double-orifice repair was only the option that we have chosen.

Dr. Giancarlo Crupi (Bergamo, Italy). To my understanding, the problem is that of a prolapsing valve, and in repairing the valve you always added a commissuroplasty at both commissures. What was the source of valve leakage? Was it central leakage, or was the leakage coming from the commissure? We have approached this kind of anomaly in a different fashion, doing an annuloplasty, starting from one commissure to the other. This will advance the mural leaflet into the so-called septal leaflet and may obviate the problem of the prolapsing valve.
Dr Macé. Thank you for your comments. Only 3 of our patients benefited from an annuloplasty. The 7 remaining patients had no annular procedures. Each of our patients had a central leakage. In our opinion, a double-orifice repair must be an option only in the presence of a valvular prolapse or restriction, not in front of an annular dilatation. Actually, when the cleft is closed, there is some restriction of the valve's movement. A double-orifice repair was also clearly a technical option for us in such situations.

Finally, I have no experience with annuloplasty, either a semicircular annuloplasty, as you described, all around the mural leaflet, or a total circular annuloplasty done to obviate the problem of the prolapsing valve. 